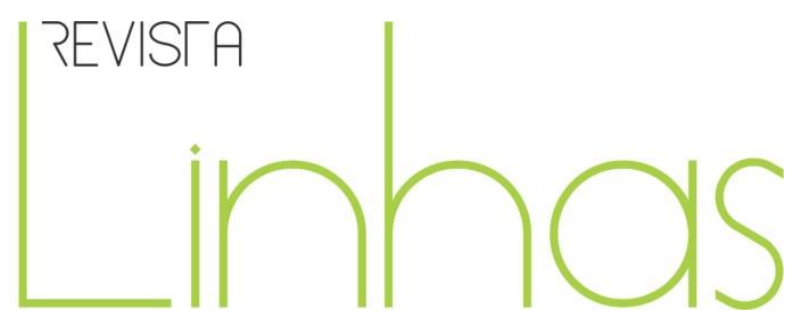

\title{
Cultura Material da Escola e escolarização no egodocumento Como e porque sou romancista, de José de Alencar (Brasil, primeira metade do século XIX) ${ }^{1}$
}

\begin{abstract}
Resumo
Neste artigo, a atenção se volta para o egodocumento Como e porque sou romancista, publicado como autobiografia, pelo brasileiro José de Alencar (1829-1877). Suas lembranças retornam ao período em que estudava no Colégio de Instrução Elementar, no Rio de Janeiro, conduzindo-nos em um relato de dois anos de duração (1840-1842). Interrogando essa empiria à luz dos conceitos de Egodocumento (VIÑAO,2000), Culturas Escolares (VIÑAO, 1995) e Cultura Material Escolar (SOUZA e PERES, 2011), o objetivo do artigo é analisar alguns vestígios da cultura material da escola e das práticas de escolarização que ela mediava na escola brasileira oitocentista conforme relatadas e significadas nesse relato autobiográfico. A hipótese é de que os elementos descritos no egodocumento de José de Alencar, ao colocarem luz sobre a escola e seu funcionamento no Oitocentos, abrem ao historiador a possibilidade de reconstituir alguns vestígios das práticas de escolarização pela mediação de uma cultura material da escola bem como de uma cultura escolar que a partir delas foi produzida.
\end{abstract}

Palavras-chave: Egodocumentos. Cultura Material da Escola. Escolarização. Século XIX.

\author{
Etienne Baldez Louzada Barbosa \\ Universidade de Brasília - UNB - \\ Brasília/DF - Brasil \\ blb_etienne@hotmail.com
}

Juarez José Tuchinski dos Anjos Universidade de Brasília - UNB Brasília/DF - Brasil juarezdosanjos@yahoo.com.br

\footnotetext{
Para citar este artigo:

BARBOSA, Etienne Baldez Louzada; ANJOS, Juarez José Tuchinski dos. Cultura Material da Escola e escolarização no egodocumento Como e porque sou romancista, de José de Alencar (Brasil, primeira metade do século XIX). Revista Linhas. Florianópolis, v. 20, n. 44, p. 154-174, set./dez. 2019.
}

DOI: $10.5965 / 1984723820442019154$

http://dx.doi.org/10.5965/1984723820442019154

\footnotetext{
${ }^{1}$ Este artigo apresenta resultados da pesquisa "Os Arquivos de Brasília e a História da Educação Brasileira no Império: inventário de fontes e perspectivas de pesquisa”, financiada pela Fundação de Amparo à Pesquisa do Distrito Federal (FAP-DF), agência de fomento à qual registramos agradecimentos. $O$ texto em tela é uma versão ampliada e bastante modificada de comunicação publicada nos Anais do Congresso "La practica educativa: historia, memoria y patrimônio" (Palma, Mallorca, 2018).
} 


\title{
Material Culture of School and schooling in the egodocument How and why I am a novelist, by José de Alencar (Brazil, first half of the $19^{\text {th }}$ Century)
}

\begin{abstract}
The present paper approached the egodocument How and why I am a novelist, published as an autobiography by the Brazilian author José de Alencar (1829-1877). His memoirs date back to the period when he studied in the Elementary Education School, in Rio de Janeiro, providing us with a two-year report (1840-1842). By examining this empiricism in the light of the concepts of Egodocument (VIÑAO, 2000), School Cultures (VIÑAO, 1995), and Material Culture of School (SOUZA and PERES, 2011), the present paper aims at analyzing some signs of the material culture of school and the educational practices that it mediated in the Brazilian schools of the nineteenth century, as reported and signified in this autobiographic report. The hypothesis is that by approaching the school and its operation in the nineteenth century, the elements described in the egodocument of José de Alencar give the historians the possibility of reconstituting some signs of the educational practices through the mediation of a material culture of school, as well as a school culture produced from them.
\end{abstract}

Keywords: Egodocuments. Material Culture of School. Schooling. $19^{\text {th }}$ Century. 
Quando pensamos em uma sala de aula, mesmo que distantes dela no tempo e no espaço, conseguimos, sem maiores dificuldades, traçar-lhe uma imagem bastante viva e que faz parte da memória de grande parte da população que teve a oportunidade de, em algum momento de sua vida - geralmente a infância e juventude -, frequentá-la. A sala de aula, essa invenção da modernidade (DUSSEL; CARUSO, 2006), cercada por uma “maquinaria” própria (VARELA; ALVAREZ-URIA, 1992), desponta nas reminiscências composta por carteiras, mesas, lousas, cadernos, lápis, murais, etc., mas também e na mediação dessa materialidade, por elementos mais abstratos e fugidios, como os saberes, os modos de fazer, os sentidos e as marcas sociais que dali se leva pela vida afora. No decorrer deste artigo, será para uma sala de aula, numa época diferente da nossa, o século XIX, que voltaremos nossa atenção, acompanhando o menino José de Alencar no seu cotidiano escolar, dos 11 aos 13 anos de idade, no Colégio de Instrução Elementar, na cidade do Rio de Janeiro, então, capital do Império do Brasil, entre os anos de 1840 a 1842 , aproximadamente.

Esse acompanhamento será feito por meio da autobiografia intitulada Como e porque sou romancista. O referido relato foi escrito em 1873, por José de Alencar (18291877), quatro anos antes do seu falecimento. Nele, o cearense (que mudou-se ao final da primeira década de vida para a cidade do Rio de Janeiro), revisita o passado e aponta, logo no início, como seria pertinente escrever para os filhos uma autobiografia literária, “onde se acharia a história das criaturinhas enfezadas, de que, por mal dos [seus] pecados [tem] povoado as estantes do Sr. Garnier" (ALENCAR, 1893, p. 08). BaptisteLouis Garnier foi um dos principais editores do Brasil na segunda metade do século XIX, sendo referência na publicação dos livros de José de Alencar (BEZERRA, 2009, p. 200). As “criaturinhas enfezadas”, por sua vez, são as personagens de suas obras, que o tornariam famoso e fariam sua fortuna no cânone literário brasileiro até os dias de hoje.

No período em que escreve seu relato, José de Alencar já era romancista conhecido e reconhecido. Cursara a Faculdade de Direito do Largo de São Francisco, em São Paulo, onde criou a revista Ensaios Literários, sendo posteriormente jornalista e redator-chefe de jornais como o Correio Mercantil e o Diário do Rio de Janeiro. Fez também carreira parlamentar, galgada desde seu acesso como deputado estadual do Ceará (1861), 
passando pela chefia da secretaria do Ministério da Justiça (1859), até sua função como Ministro da Justiça (1868-1870). A autobiografia narra, em detalhes, essa trajetória: a infância vivida na casa número 55, da Rua do Conde, na capital do Império, onde residia na companhia da mãe e irmãos e recebia, com frequência, a visita do pai, o padre e Senador José Martiniano de Alencar; suas experiências escolares na infância e juventude; sua iniciação na literatura, no jornalismo e na política e as influências que esse conjunto de eventos teria exercido na sua formação como escritor. Por conta desse conteúdo, seu relato é, sem dúvida, um precioso documento sobre a vida ordinária das classes favorecidas do Império, pela ótica de um de seus membros.

São de grande interesse, para o historiador da educação, notadamente, as páginas iniciais da autobiografia, nas quais José de Alencar oferece um testemunho revelador sobre o cotidiano de sua escolarização, entre os anos de 1840-1842, legando-nos sua visão pessoal sobre essa experiência - "ser escolarizado" - que, paulatinamente, tornou-se cada vez mais frequente na vida das crianças brasileiras daquela época, mas cujo ponto de vista infantil - ou o que dele sobreviveu em relatos como o de Alencar - ainda é pouco estudado na historiografia da educação em nosso país. Diante disso e fazendo um recorte na potencialidade dessa documentação, nosso objetivo neste artigo é analisar alguns vestígios da cultura material da escola e das práticas de escolarização que ela mediava na escola brasileira oitocentista, conforme narradas e significadas no relato autobiográfico de José de Alencar.

Para interrogar a autobiografia enquanto evidência histórica, a estamos, aqui, considerando como um egodocumento - texto em que o escritor é autor e sujeito presente na narrativa, deixando suas marcas e referências na escrita, falando de si (VIÑAO, 2000). Perspectivar dessa forma o relato impõe reconhecer que o texto de ego não é neutro, mas fruto de uma produção de memória que constrói uma imagem do passado por meio de vestígios concretos, elaborando sobre eles um significado (POLLACK, 1992). Nesse sentido, o relato alencariano não nos dá acesso a uma realidade dos acontecimentos descritos; todavia, nos permite adentrar numa interpretação autorreferencial do egoautor sobre ela, em um movimento que desvela ou oculta (PERROT, 2009) parcelas do seu passado individual que é, ao mesmo tempo, social. Movendo-nos entre lembranças e esquecimentos, mas, sobretudo, colocando nossa 
atenção nos significados e percepções da escola, das suas práticas e da sua materialidade gravados, recordados e registrados pelo egoautor, é que procuraremos, a partir da interpretação que sobre esses fenômenos ele construiu, perseguir o objetivo acima proposto.

A hipótese que nos norteia é de que os elementos descritos no egodocumento de José de Alencar, ao colocarem luz sobre a escola e seu funcionamento no Oitocentos, abrem ao historiador a possibilidade de reconstituir alguns vestígios das práticas de escolarização pela mediação de uma cultura material da escola bem como de uma cultura escolar que a partir delas foi produzida. Eleger a cultura escolar como eixo de análise é considerar a escola como espaço de institucionalização do saber, que produz e transmite cultura, hábitos e valores e que, portanto, possui uma configuração que lhe é própria, sem deixar de fazer parte da sociedade em que se insere. De modo sucinto, quando pensamos em uma cultura escolar, estamos evocando, com Antonio Viñao (1995), os elementos que são legitimados e institucionalizados no cotidiano da escola (os modos de pensar e fazer, a organização do espaço, a materialidade que a compõe).

Sobre esse último aspecto, o relato de José de Alencar faz referência a utensílios próprios da escola, o que nos leva, por conseguinte, a atentar para uma certa noção de cultura material escolar - aqui compreendida, com Gizele de Souza e Eliane Peres, enquanto "o conjunto de artefatos materiais em circulação e uso nas escolas, mediados pela relação pedagógica, que é intrinsecamente humana, reveladora da dimensão social" (SOUZA; PERES, 2011, p. 56). Realmente, através da dimensão material, a cultura da escola se manifesta e se organiza, tanto nos usos e sentidos conferidos aos objetos pertencentes à escola, como nas experiências escolares que através deles são produzidas no espaço histórico da sala de aula. Não se trata de somente arrolar aqui os objetos e práticas identificados no egodocumento, porém pensar as ações e a materialidade em uma perspectiva cultural da escola, imbricada nas relações sociais e nos modos de produção de sentidos e sensibilidades, que contribuíram para a formação do futuro parlamentar e do conceituado romancista brasileiro, no século XIX. É disso tudo que nos ocuparemos a seguir. 
Após os preâmbulos explicativos do seu texto de ego, José de Alencar apresenta ao leitor aquele que foi o início do que considerava o caminho que contribuiu para que se tornasse romancista: a escola denominada "colégio de meninos" ou "Colégio de Instrução Elementar":

Quando me recolho da labutação diária com o espírito mais desprendido das preocupações do presente, e sucede-me ao passar pela Rua do Lavradio pôr os olhos na tabuleta do colégio, que ainda lá está na sacada do $\mathrm{n}^{\circ} .17$, mas com diversa designação; transporto-me insensivelmente àquele tempo, em que de fraque e boné, com os livros sobraçados, eu esperava ali na calçada fronteira o toque da sineta que anunciava a abertura das aulas. Toda a minha vida colegial se desenha no espírito com tão vivas cores, que parecem frescas de ontem, e, todavia, mais de trinta anos já lhes pairaram sobre. Vejo o enxame dos meninos, alvoroçando na loja, que servia de saguão; assisto aos manejos da cabala para a próxima eleição do monitor geral; ouço o tropel do bando que sobe as escadas, e se dispersa no vasto salão, onde cada um busca o seu banco numerado. Mas, o que sobretudo assoma nessa tela é o vulto grave de Januário Matheus Ferreira, como eu o via passeando diante da classe, com um livro na mão e a cabeça reclinada pelo hábito da reflexão. (ALENCAR, 1893, p. 09-10)

Encontra-se, nesse excerto, o endereço do colégio, a sua identificação (na tabuleta), o uniforme usado pelos alunos (fraque e boné), o objeto do trabalho do educando que era carregado embaixo dos braços (livros), o dispositivo que informava que a aula começaria e regulava os tempos escolares (sineta), diversas pistas de que ali funcionava uma classe de ensino mútuo ("enxame” de meninos, eleição do monitor geral, vasto salão, banco numerado) e a figura do professor munido com o livro e passeando pelas classes. Esses objetos, espaços e mobílias de organização dos ritos escolares "se não se apresentam imediatamente como registros documentais do passado, portam vestígios das práticas escolares instituídas historicamente" (VIDAL, 2005, p. 04). Assim, é fundamental indagar o que esses elementos materiais testemunham sobre a escolarização e as culturas da escola no período aqui flagrado no egodocumento alencariano, mais precisamente, os anos de 1840-1842. 
O trecho acima, no bojo das memórias do egoautor, inicia situando a escola - com todas as especificidades próprias da cultura que ela produz - na geografia da cidade, mais especialmente, de uma de suas ruas. Conforme Alencar, ela estaria erguida no número 17 da Rua do Lavradio, na cidade do Rio de Janeiro. Sabe-se que a Rua mencionada recebeu o nome do responsável pela sua abertura, o Marquês do Lavradio e que, ao longo do século XIX, contribuiu para a vida artística, política e social da capital imperial. Nela fixaram residência ou comércio pessoas "famosas" da época , tais como o tipógrafo Laemmert, o Regente do Império Araújo Lima (Marquês de Olinda), os engenheiros André Rebouças e Vieira Souto, o médico José Pereira Rego (Barão de Lavradio), bem como casas de teatro e maçonaria.

Sobre a cidade e seus processos de urbanização, é pertinente destacar, a partir de Alessandra Schueller (1999), que a melhoria dos serviços e das estruturas urbanas acontecia desde a década de 1830, mas, no momento em que o egoautor a conheceu e percorreu no tempo de sua meninice, a maioria da população do Império ainda permanecia vinculada ao meio rural. Somente na segunda metade do Oitocentos momento em que ele recorda sua infância e, ao percorrer a mesma rua de sua escola, revela que o endereço ainda era ocupado por uma instituição escolar, conquanto não a mesma que conhecera em criança - é que os paradigmas de "civilização" e "progresso" ganham força, com referenciais europeus e norte-americanos, intensificando a vida urbana e as construções de prédios públicos (SCHUELLER, 1999). É, assim, lembrando desse colégio no coração da cidade e das relações para ele indissociáveis entre essas duas realidades e culturas - cujas fronteiras, de modo palpável, eram demarcadas pela mesma plaqueta de identificação do estabelecimento - que começa a se desenrolar uma "revivência" de experiências escolares de outrora, todas, marcadas pelo ritmo de outro tanto de elementos tangíveis e materiais da escolarização pretérita. 
A escola aqui evocada não era uma escola pública, mas particular, nascida daquela constante colaboração na história da educação brasileira entre o público e o privado, colaboração ocasionada, dentre outros fatores, pelas dificuldades encontradas pelo Estado em formação de oferecer a toda a população a instrução elementar, o que deu ensejo para a permanência de redes paralelas de ensino, como a doméstica e a das instituições particulares (XAVIER, 2003). Ademais, sabemos, tanto pela via historiográfica (FARIA FILHO; VIDAL, 2000) quanto por evidências da literatura brasileira da época (ALMEIDA, 2011) que na primeira metade do Oitocentos os nomes generalizados para designar as escolas de instrução elementares públicas eram os de "escolas régias", "aulas régias" ou "aulas de primeiras letras”. Já o nome Colégio, aqui, parece remeter-se mesmo a uma escola particular, dada a referência à existência de um diretor e vários professores responsáveis por diferentes matérias (ALENCAR, 1893). Colégios nascidos não apenas para suprir a falta de escolas públicas, mas, também, para oferecer instrução diferenciada aos filhos das famílias mais abastadas, ao sabor das modas pedagógicas - a da época, o ensino mútuo - e dos interesses de classe, sobretudo, a formação literária, isto é, de viés humanista.

A propósito, qual seria o perfil social dos alunos do colégio? Alguns indícios do perfil social favorecido de José de Alencar e seus colegas podem ser flagrados - além do fato de estudar em uma escola particular e da própria trajetória biográfica que veio a ter na referência à indumentária escolar que afirma ter tido na infância, o fraque e o boné. $A$ pobreza dos estudantes, ao longo do século XIX, foi sem dúvida um dos grandes obstáculos materiais à institucionalização da escola elementar no Brasil, a ponto de muitos pais não enviarem os filhos a escola por sequer terem roupas com as quais vestir a prole (ANJOS; SOUZA, 2015). Nosso egoautor, ao contrário, ia bem vestido - conquanto ainda não se tratasse daquelas roupas infantis masculinas, compostas de camisas e calções curtos, que aos poucos se popularizariam no século XIX como trajes distintivos da meninice (ARIÈS, 1978; MAUAD, 1999) - e ainda trazia, debaixo do braço, os livros a serem utilizados para o estudo. Possuía, assim, recursos materiais que o diferenciavam de boa parte dos escolares daquela época, sobretudo, os alunos das escolas de primeiras 
letras públicas, que quase sempre dependiam inteiramente dos cofres públicos para serem providos de penas, papel, tinta e compêndios escolares.

4.

A remissão ao "enxame" de meninos, eleição do monitor geral, vasto salão, banco numerado e da sineta a regular os tempos educativos parecem indicar a utilização, no Colégio de Instrução, do método de ensino mútuo. Até por volta dos anos 1840, no Brasil, tal método foi alçado à categoria de inovação e modernidade pedagógica, pela racionalidade que, em contraponto ao ensino individual, imprimia ao ensino de massas, justamente num momento em que se queria ampliar o alcance da escola a diversos grupos sociais, na medida em que se via nela uma eficaz ferramenta de governabilidade (FARIA FILHO et al., 2006).

Nas escolas públicas a utilização desse método foi revelando-se problemática, pela falta de condições materiais, como a ausência de amplas salas que pudessem comportar as turmas organizadas em classes e de utensílios como tabelas e cartazes (INÁCIO, 2004). Essa carência, no período que o egodocumento alencariano permite flagrar, não ocorria na escola particular que ele frequentara, devidamente equipada para a prática do ensino pelo método monitorial, fosse com um vasto salão ou com os bancos numerados, as sinetas a controlar os tempos e a eleição de monitores já naturalizada na cultura escolar local.

Outra evidência que sugere a utilização do método mútuo na escola frequentada por José de Alencar é seu relato sobre o empenho discente em ocupar o primeiro lugar na turma a título de prêmio, ambição partilhada por ele e seus colegas, causa de alegria e tristeza infantil - mas prova clara do efeito que a emulação, um dos pilares do método lancasteriano (SANTI; CASTANHA, 2013), conseguia, de fato, exercer sobre os escolares. Foi que aconteceu no dia em que perdeu o posto de "primeiro da classe" para um colega, que sendo chamado antes dele, soube - com alguma condescendência do diretor do colégio, ao que parece - dar a resposta correta para ser galardoado com o posto até então ocupado pelo nosso egoautor: 
Meu imediato e êmulo, que me foi depois amigo e colega de ano em $\mathrm{S}$. Paulo, era o Aguiarzinho (Dr. Antonio Nunes de Aguiar), filho do distinto general do mesmo nome (...) Ansioso aguardava ele a ocasião de se desforrar da partida que eu lhe havia ganho, depois de uma luta porfiada - Todavia, não lhe acudiu a resposta de pronto; e passaria a sua vez se o diretor não lhe deixasse tempo bastante para maior esforço do que fora dado aos outros e sobretudo a mim - Afinal, acorreu-lhe a resposta e eu com o coração transido cedi ao meu vencedor o lugar de honra que tinha conquistado de grau em grau e conseguira sustentar havia mais de dois meses. Nos trinta anos vividos desde então, muita vez fui esbulhado do fruto do meu trabalho pela mediocridade agaloada; nunca senti senão o desprezo que merecem tais pirraças da fortuna, despeitada contra aqueles que não a incensam. Naquele momento, porém, vendo perdido o prêmio de um estudo assíduo e mais por surpresa do que por deficiência, saltaram-me as lágrimas que eu traguei silenciosamente, para não abaterme ante a adversidade. (ALENCAR, 1893, p. 13-14)

O relato acima, em termos de uma etno-história da escola, é denotador tanto de culturas infantis - aquele "conjunto estável de atividades ou rotinas, artefatos, valores, interesses que as crianças produzem e compartilham na interação com seus pares" (CORSARO, 2009, p. 32) - quanto das culturas escolares. Mostra como questões surgidas nos pátios do recreio ou fora da sala de aula - pelo visto, uma briga entre os dois meninos, das quais um saiu perdedor - podia vir a ser resolvida, também de forma competitiva, mas com o acréscimo significativo das referências vindas do admirável mundo novo da escola e das culturas que Ihe são próprias, em sala de aula, nas competições ensejadas pelo método mútuo, então utilizado no estabelecimento.

Se na percepção do egoautor, mesmo muitos anos mais tarde, ficou gravada a experiência da frustração e da derrota (quando não a do ressentimento, que mostramos em outro estudo (ANJOS; BARBOSA, 2018a) ter sido sentimento-ingrediente na história da educação brasileira), também é certo que já, naquele momento de sua infância, o método de Lancaster cumpria eficazmente seu papel, levando os alunos a desenvolverem a crença no esforço pessoal e na competitividade entre os pares como via educativa, valores tão apreciados naquela sociedade de liberalismo tópico em consolidação. 
A lembrança da sineta, a anunciar o início dos trabalhos escolares, é evidência que igualmente merece de nossa parte algum esforço de interpretação. Ela confirma, uma vez mais, aquilo que Rita de Cássia Gallego (2008) já teve oportunidade de observar: a produção de um tempo próprio da escola e de ritmos temporais a organizarem e marcarem o funcionamento dessa instituição foi processo histórico fundamental para sua institucionalização entre nós e que antecedeu, em muito, ao surgimento da escola primária graduada. Antes, já vinha se estabelecendo desde os tempos do Império (GALLEGO, 2008). Entrementes, no contexto em tela, essa evidência parece relacionarse ao uso do método lancasteriano, que tinha como uma de suas vantagens o emprego racional do tempo com vistas à obtenção de melhores resultados na escolarização, razão pela qual "as sinetas, os apitos, as campainhas (...) eram fundamentais diante da proposta de instruir um grande número de alunos" (INÁCIO, 2004, p. 33). Como esses usos do tempo foram percebidos e apreendidos por José de Alencar em seu egodocumento?

A aplicação adequada e eficaz do tempo era, sobretudo, uma preocupação docente. Tanto é que o diretor do colégio - personagem sobre o qual nos aprofundaremos com mais vagar na próxima seção -, ao perceber que alguma das classes sob a responsabilidade de determinado professor não estava no nível esperado, mas atrasada, "demorava-se com ela dias e semanas, até que obtinha adiantá-la e só então a restituía ao respectivo professor" (ALENCAR, 1893, p. 11). Por outro lado, face uma classe “em dia”, isto é, com o aprendizado adequado ao tempo previsto de escolarização, encaminhando-se para o momento dos exames, a atitude era outra, conquanto visando otimizar o tempo disponível para os trabalhos escolares: “Meado o ano, porém, o melhor dos cuidados do diretor voltava-se para as últimas classes, que ele se esmerava em preparar para os exames. Eram estes dias de gala e de honra para o colégio, visitado por quanto havia na Corte de ilustre em política e letras" (ALENCAR, 1893, p. 11).

Como se nota, diante de diferentes demandas - atraso ou proximidade do fim do processo de escolarização - o diretor apropriava-se também de forma diferenciada do tempo de que dispunha no Colégio para realizar a instrução dos meninos sob seus cuidados. O tempo era, assim, para ele, algo tangível e perceptível e cujo bom uso, no 
caso dos exames, seria devidamente observado e notado pelos ilustres assistentes que viriam prestigiar o trabalho educativo ali realizado ou para recuperar o atraso dos meninos que, mais dia, menos dia, também precisariam chegar ao ponto de serem examinados.

Mas, o tempo também era, em certa medida, percebido pelos alunos, embora não como um fator de preocupação ou racionalidade pedagógica, como no caso do diretor. Antes, parece que funcionava como um marcador de espaços, atividades e rotinas diárias que, de forma naturalizada, ia se incutindo nos meninos bem como de experiências e subjetividades individuais e coletivas. Sobre tudo isso, ainda referindo-se ao dia em que perdeu o posto de primeiro da sua classe, escreve José de Alencar:

Nossa classe trabalhava em uma varanda ao rés do chão, cercada pelo arvoredo do quintal. Quando, pouco antes da Ave-Maria, a sineta dava sinal da hora de encerrar as aulas, Januário fechava o livro e com o tom breve do comando ordenava uma espécie de manobra que os meninos executavam com exatidão militar.

Por causa da distância da varanda, era quando todo o colégio já estava reunido no grande salão e os meninos em seus assentos numerados, que entrava em passo de marcha a sexta classe à cuja frente vinha eu, o mais pirralho e enfezadinho da turma em que o geral se avantajava na estatura, fazendo eu assim as vezes de um ponto.

A constância com que me conservava a frente da classe no meio das alterações que em outras se davam todos os dias, causava sensação no povo colegial; faziam-se apostas de lápis e canetas; e todos os olhos se voltavam para ver se o caturrinha do Alencar $2^{\circ}$ (era o meu apelido colegial) tinha afinal descido de monitor de classe.

O general derrotado, a quem a sua ventura reservava a humilhação de assistir à festa da vitória, jungido ao carro triunfal de seu êmulo, não sofria talvez a dor que eu então curti, só com a ideia de entrar no salão, rebaixado do meu título de monitor e rechaçado para o segundo lugar.

$\mathrm{Se}$, ao menos tivesse se dado o fato no começo da lição, restava-me a esperança de com algum esforço recuperar o meu posto; mas por cúmulo da infelicidade sobreviera o meu desastre justamente nos últimos momentos, quando a hora estava a findar.

Foi no meio dessas reflexões que tocou a sineta e as suas badaladas ressoaram em minha alma como o dobre de uma campa.

Mas Januário, que era acerca de disciplina colegial de uma pontualidade militar, não deu pelo aviso e amiudou as perguntas, percorrendo apressadamente a classe. Poucos minutos depois eu recobrava meu lugar, e erguia-me trêmulo para tomar a cabeça do banco.

O júbilo que expandiu a fisionomia sempre carregada do diretor, eu próprio não o tive maior, com o abalo que sofri. Ele não se pode conter a abraçou-me diante da classe. 
Naturalmente a questão proposta e cuja solução deu-me a vitória, era difícil; e por isso atribuía-me ele um mérito que não provinha talvez senão da sorte, para não dizer do acaso.

Momentos depois entrava eu pelo salão à frente da classe, onde me conservei até o exame. (ALENCAR, 1893, p. 14-15, grifos nossos)

A aceitarmos a definição de Clifford Geertz no seu diálogo com Max Weber, "que o homem é um animal amarrado a teias de significados que ele mesmo teceu" e assumirmos com ele "a cultura como sendo essas teias e sua análise (...) não como uma ciência experimental em busca de leis, mas como uma ciência interpretativa à procura do significado" (GEERTZ, 2008, p. 4), temos, no trecho supracitado, muitas informações a interpretar.

O egodocumento alencariano - ainda que focado em apresentar ao leitor o desfecho do episódio da perda seguida pela recuperação do posto de monitor e primeiro da classe - vai indicando-nos uma série de elementos e usos do tempo na rotina da escolarização: 1) a hora da Ave-Maria, isto é, por volta das 18h, momento em que tradicionalmente a Igreja Católica recorda a anunciação do Anjo à Virgem, marcava o final dos trabalhos escolares do colégio. 2) A sineta, funcionava, então, como lembrete sonoro sensível e ponto de transição temporal para outra atividade, possivelmente, a ceia; 3) Também o gesto do professor de fechar o livro e dar voz de comando - este último, característica indelével do método de Lancaster e mecanismo para coordenar a boa ordem das classes - confirmava aos alunos o término das atividades diárias e encaminhava-os para a seguinte; 4) apesar da pontualidade, naquele dia, o professor decidiu indagar um pouco mais a turma, como que dando uma nova chance para Alencar que, com certa dose de sorte, conseguiu, apesar de esgotado oficialmente o tempo dedicado às atividades escolares do dia, recuperar seu posto e voltar a ser o "Primeiro da turma".

Há, por outro lado, elementos mais subjetivos, experimentados tanto individualmente como coletivamente na relação dos estudantes com os tempos diários da escola. Nesse sentido, para Alencar adulto falando de si em menino, foi deveras angustiante a percepção de que, se sua derrota tivesse se dado no início dos trabalhos escolares diários, teria tido tempo para reverter o que considerava uma derrota injusta; 
mas, como se dera no fim - quando o marcador temporal insistia que outra atividade devia ter lugar - não fosse o "abuso" do relógio cometido pelo diretor (decidindo-se a fazer uma última sabatina na classe), teria de contentar-se em ser objeto de chacota dos colegas. Para todos eles, de fato, o fim do dia era o momento em que, coletivamente, podiam contemplar as glórias e dores dos pares (além de ganhar uns lápis ou canetas apostados para tornar mais saboroso o momento), movimentados para cima ou para baixo, isto é, promovidos ou rebaixados do posto de primeiro da turma, a depender do andamento das atividades escolares e do êxito obtido nelas ou não. Em tudo isso, como se vê, é o tempo, sempre ele, o elemento fugidio que, para ser notado, apoia-se em elementos materiais e simbólicos, como a sineta, os comandos do mestre, a hora da AveMaria, dentre outros. Dele, nem os professores nem os estudantes escapavam, ainda que por ele tocados de formas diferenciadas, mas fortes o suficiente para serem lembrados, mesmo, muito tempo depois, por quem o vivenciou na infância.

A presença do livro no relato alencariano - seja debaixo do seu braço ou do professor ou, ainda, sobre a mesa a ajudar a materializar a percepção da transição dos tempos da escola - também é esclarecedora. Na tradição educativa ocidental, a partir da Idade Média, o livro sempre figurou como a autoridade do saber (VERGER, 1999) e, mesmo nos albores da escola moderna, a partir das transformações ocasionadas pelo surgimento da prensa tipográfica, um pedagogo como Comênius considerava que este era indispensável ao ensino, como instrumento essencial para aquisição de novos conhecimentos (MUNAKATA, 2001). O século XIX ainda atribuía essa importância capital ao impresso escolar, tanto que no caso brasileiro, boa parte da escolarização estava calcada mais na leitura do que na escrita, sobretudo, nas décadas iniciais do Oitocentos. Como destaca Diana Vidal (2000), o ensino da leitura generalizou-se com mais facilidade na escolarização oitocentista por ser mais barato e rápido que o da escrita, que por sua vez, era mais moroso e exigia mais materiais. Assim, a referência ao livro nas memórias de Alencar testemunha não só sua relação com esse impresso ao longo da vida (afinal, tornou-se escritor), mas, também, a centralidade desse utensílio na educação das crianças brasileiras do período que estamos visitando. Vale a pena ensaiarmos uma 
interpretação acerca das experiências que o livro e a leitura ocuparam na sua vivência escolar e no modo como mediaram algumas relações pedagógicas e culturas escolares.

Cotejando o egodocumento com fontes da época, descobre-se que o Colégio de Instrução Elementar contava com dois diretores: José da Costa Azevedo (diretor científico) e Januário Matheus Ferreira (diretor econômico) - de quem falamos na seção anterior e que, dentre suas funções, realizava os exames anuais dos alunos (LEVA..., 1846). Sobre o segundo diretor, José de Alencar rememora:

Januário era talvez ríspido e severo em demasia; porem nenhum professor o excedeu no zelo e entusiasmo com que desempenhava o seu árduo ministério. Identificava-se com o discípulo; transmitia-lhe suas emoções e tinha o dom de criar no coração infantil os mais nobres estímulos, educando o espírito com a emulação escolástica para os grandes certames da inteligência. (ALENCAR, 1893, p. 10)

Até os calçados do diretor serviam para demarcar a gravidade e seriedade de sua presença entre os meninos: "Usava ele de sapatos rinchadores [sic]; nenhum dos alunos do seu colégio ouvia de longe aquele som particular, na volta de um corredor, que não sentisse um involuntário sobressalto" (ALENCAR, 1893, p. 10).

Acompanhar essas representações do papel desempenhado pelo diretor - ora aquele que é severo e ríspido, cujo próprio barulho dos calçados é suficiente para sobressaltar; ora aquele que se identifica com o aluno, educando-o e emulando-o - é perceber que essas características estão imbuídas por uma construção de memória, por uma formulação feita pelo adulto, que considerou os fatos recordados em conjunto com o aproveitamento decorrente da prática do diretor para a vida do aluno. O adulto José de Alencar, ao revisitar suas memórias, identifica positivamente a prática do diretor, uma vez que ele conseguia desenvolver cognitivamente os alunos.

O Colégio de Instrução Elementar contava com uma média de 14 professores, que se alternavam em turmas específicas (COLÉGIO..., 1848). José de Alencar pontua que “dividia-se o diretor por todas as classes, embora tivesse cada uma seu professor especial; desse modo andava sempre ao corrente do aproveitamento de seus alunos, e trazia os mestres como os discípulos em constante inspeção" (ALENCAR, 1893, p. 10). 
João Barroso (2004) aponta que uma das marcas da cultura escolar é conseguir homogeneizar normas, espaços, tempos (dos alunos, dos professores, dos saberes) e os processos de inculcação. Nesse sentido, percebemos o princípio da homogeneidade na prática do diretor Januário, uma vez que, mesmo com professores distintos para cada classe, ele exercia o papel docente - ao examinar o aproveitamento dos alunos, indicar leituras, escolher monitores - e o papel de inspetor do ensino, fiscalizando os próprios docentes. Esse modo de agir do diretor contribuía para que todos do colégio, professores e alunos, se atentassem para a existência de um processo de organização pedagógico único e harmônico, de resto, meta do próprio método mútuo.

Quando relembra o seu período na escola, José de Alencar enfatiza sempre a figura do diretor do Colégio de Instrução Elementar e do livro como, instrumento didático e companhia constante desse personagem: “mas o que sobretudo assoma nessa tela é o vulto grave de Januário Matheus Ferreira, como eu o via passeando diante da classe, com um livro na mão e a cabeça reclinada pelo hábito da reflexão" (ALENCAR, p. 1893, 10, grifos nossos). Noutra passagem - aquela relativa ao prêmio perdido, causa de mágoa e sofrimento na infância de Alencar -, de novo, emerge a figura do diretor acompanhado do livro, quase que despretensiosamente, na narrativa egodocumental: "Uma tarde, ao findar a aula, houve pelo meio da classe um erro. - Adiante, disse Januário, sem altear a voz, nem tirar os olhos do livro" (ALENCAR, 1893, p. 12). O livro, bem o sabemos, era nessa escola e na escolarização então generalizada no Brasil instrumento indispensável e, para o historiador da educação, forte evidência do valor atribuído à leitura naquele contexto. De fato, ao avaliar o legado do mestre/diretor Januário à sua formação, o egoautor assim se expressou:

Aos onze anos [eu] não conhecia uma só palavra de língua estrangeira, nem aprendera mais do que as chamadas primeiras letras. Muitos meninos, porém, que nessa idade tagarelam em várias línguas e já babujam nas ciências, não recitam uma página de Frei Francisco de S. Luís ou uma Ode do Padre Caldas, com a correção, nobreza, eloquência e alma que Januário sabia transmitir a seus alunos. Essa prenda que a educação deu-me para tomá-la pouco depois, valeu-me em casa o honroso cargo de ledor, com que eu me desvanecia; como nunca me sucedeu depois no magistério ou no parlamento. (ALENCAR, 1893, p. 17, grifo nosso) 
As referências (e reverências) às habilidades educativas do diretor do Colégio correção, nobreza, eloquência e alma com que ensinava e recitava -, todas elas, estão ligadas ao aprendizado da correta leitura em voz alta, prática bastante apreciada entre as classes abastadas do Império, que começavam, por aquela época, a imitar as práticas da burguesia europeia materializadas nos serões familiares, serões, inclusive, realizados na casa da própria família Alencar e nos quais o nosso egonarrador ocupava o cargo de "ledor" (ANJOS e BARBOSA, 2018b). Teria sido esse, por sinal, o grande legado que, no futuro, o romancista consideraria ter adquirido na infância, por força da ação educativa de Januário Mateus Ferreira. Todavia, apesar da centralidade do livro e da leitura, não foi só isso que o menino aprendeu nos anos de colégio. Nesse sentido, o cotejamento do egodocumento com fontes da época é, novamente, bastante esclarecedor.

Sobre a aquisição de conhecimentos durante a fase de escolarização, José de Alencar resume: "sabíamos pouco; mas esse pouco, sabíamos bem” (ALENCAR, 1893, p. 16). Conforme pudemos apurar no Almanak Administrativo, Mercantil e Industrial do Rio de Janeiro - ainda que para um período pouco posterior àquele em que o egoautor ali esteve - no Colégio de Instrução Elementar ensinava-se: leitura e ortografia, caligrafia, noções de ideologia e gramática geral, aritmética, religião (instrução primária) (ALMANACK, 1848). Recorrendo à imprensa periódica carioca, no ano de 1840, o resultado dos exames finais da $1^{\text {a }}$ classe do Colégio de Instrução Elementar comparece nas páginas de dois jornais na província do Rio de Janeiro. Por meio da publicação, sabese que 19 alunos fizeram o exame final, sendo 2 aprovados simplesmente, 9 plenamente e 8 com adiantamento. O menino José Martiniano de Alencar foi aprovado plenamente em leituras prosaicas, leituras poéticas, caligrafia, aritmética, gramática prática e em doutrina cristã (DECLARAÇÕES..., 1840; COLÉGIO DE INSTRUÇÃO ELEMENTAR..., 1840). No confronto das disciplinas ministradas no colégio com o resultado de José de Alencar nos exames finais, percebe-se que ele conseguiu, ao menos aos olhos dos examinadores, aquilo que relembra no seu relato: saber bem o que foi ensinado. Tendo a leitura como um dos eixos formativos, mas também adquirindo os outros rudimentos que, no período, constituíam a instrução elementar. 
Como pontua Roger Chartier (2002), a leitura "é prática criadora, atividade produtora de sentidos singulares, de significações de modo nenhum redutíveis às intenções dos autores de textos ou fazedores de livros, ela é uma caça furtiva" (CHARTIER, 2002, p. 123). Nesse sentido, acompanhando o egodocumento de José de Alencar, realizamos nossa busca por aquilo que não estava por ele declarado abertamente, mas que por nós pôde ser observado sob a luz da análise histórica: as práticas de escolarização por meio da medicação de uma cultura material da escola e de uma cultura escolar.

A trajetória aqui percorrida permitiu-nos localizar a escola particular cursada por José de Alencar, o tipo de vestimenta utilizada, o método (ensino mútuo), os tempos próprios da escola, a rotina de escolarização, a materialidade por meio do livro didático e a utilização da leitura como eixo formativo. Essas categorias de análise aqui nos auxiliaram na constatação de que a escolarização acompanhada evidencia elementos muito próprios, pessoais de José de Alencar, mas coaduna com a forma escolar encontrada no século XIX, que, como pondera Maria Cristina Soares de Gouvêa (2007), sofria dificuldades em sua consolidação e suporte financeiro do Estado, "com um projeto de educação ao mesmo tempo inclusivo e excludente" (GOUVÊA, 2007, p. 138).

No caso de José de Alencar, que pôde estudar em uma escola particular, com vastos salões e bancos numerados, tendo papel de destaque como monitor, a inserção educacional não foi excludente. A escrita de seu egodocumento demonstra experiências coletivas e individuais, que perpassam a memória, o afeto, o sentir e o utilizar, o material e o imaterial, contribuindo para o conhecimento sobre a escola e o seu funcionamento no século XIX. 


\section{Referências}

ALENCAR, José de. Como e porque sou romancista. Rio de Janeiro: Leuzinger, 1893.

ALMANAK administrativo, mercantil e industrial do Rio de Janeiro (1844-1885). Rio de Janeiro.

ALMEIDA, Manoel Antonio de. Memórias de um sargento de milícias. Brasília: Edições da Câmara, 2011.

ANJOS, Juarez José T. dos; BARBOSA, Etienne Baldez Louzada. Memória, história e ressentimentos na Instrução Pública Primária na Província do Paraná (Brasil, 1853-1889). Educação. Santa Maria, v. 43, n. 41, p. 791-806, out./dez. 2018 a.

ANJOS, Juarez José T. dos; BARBOSA, Etienne Baldez Louzada. Práticas de leitura doméstica na autobiografia de um parlamentar do Brasil Império, 1840-1842. in: MEDA, Juri et al. (orgs.). La practica educativa: historia, memoria y patrimonio. Salamanca: FarenHouse, 2018b, p. 471-480.

ANJOS, Juarez José T. dos; SOUZA, Gizele de. Rememorando a escola e seus objetos: cultura material escolar e memórias de infância (Paraná 1870-1900). CONGRESSO BRASILEIRO DE HISTÓRIA DA EDUCAÇÃO, 8. Anais... Maringá: 2015, p. 1-15.

ARIÈS, Philippe. História social da criança e da família. Rio de Janeiro: Zahar, 1978.

BARROSO, João. Políticas educativas e administração escolar. Lisboa: Universidade Aberta, 2004.

BEZERRA, Carlos Eduardo de Oliveira. Adolfo Caminha: um polígrafo na literatura brasileira do século XIX (1885-1897). São Paulo: Cultura Acadêmica, 2009.

CHARTIER, Roger. A história cultural entre práticas e representações. Lisboa: [s.n.], 2002.

COLÉGIO DE INSTRUÇÃO ELEMENTAR. RESULTADO DOS EXAMES NO TERCEIRO ANO DESTE ESTAEBELECIMENTO. Jornal do Comércio. Rio de Janeiro, n. 337, p. 3, 21 dez. 1840.

CORSARO, William. Métodos etnográficos no estudo da cultura de pares e das transições iniciais da vida das crianças. In: MÜLLER, Fernanda; CARVALHO, Ana Maria Almeida (orgs.). Teoria e prática na pesquisa com crianças: diálogos com William Corsaro. São Paulo: Cortez, 2009.

DECLARAÇÕES Colégio de Instrução Elementar. O Despertador. Rio de Janeiro, n. 857, p. 2, 20 dez. 1840.

DIÁRIO DO RIO DE JANEIRO. Rio de Janeiro, 9 de fevereiro de 1846. 
DUSSEL, Inês; CARUSO, Marcelo. La invención del aula: una genealogia de las formas de enseñar. Buenos Aires: Santilana, 2006.

FARIA FILHO et al. Escola, política e cultura. Belo Horizonte: Argumentum, 2006.

FARIA FILHO, Luciano Mendes de; VIDAL, Diana Gonçalves. Os tempos e os espaços escolares no processo de institucionalização da escola primária no Brasil. Revista Brasileira de Educação. Campinas, n. 14, p. 19-34, mai./ago. 2000.

GALLEGO, Rita de Cássia. Tempo, temporalidades e ritmos nas escolas primárias públicas em São Paulo: heranças e negociações (1846-1890). 2008. Tese (Doutorado em Educação) - Faculdade de Educação da Universidade de São Paulo, São Paulo, 2008.

GEERTZ, Clifford. A interpretação das culturas. Rio de Janeiro: LTC, 2008.

GOUVÊA, Maria Cristina Soares de. A escolarização da criança brasileira no século XIX: apontamentos para uma re-escrita. Revista Educação em Questão, Natal, v. 28, n. 14, p. 121-146, jan./jun.2007.

INÁCIO, Marcilaine Soares. O processo de escolarização e o ensino de primeiras letras em Minas Gerais (1825-1852). In: VAGO, Tarcísio Mauro; GOUVÊA, Maria Cristina Soares de (orgs.). Histórias da educação: histórias da escolarização. Belo Horizonte: HG Edições, 2004, p. 23-36.

JORNAL DO COMERCIO. Rio de Janeiro, 21 de dezembro de 1840.

LEVA ao Conhecimento... Diário do Rio de Janeiro. Rio de Janeiro, n. 7131, p. 3, o9 fev. 1846.

MAUD, Ana Maria. A vida das crianças da elite durante o Império. In: DEL PRIORE, Mary (org.) História das Crianças no Brasil. São Paulo: Contexto, 1999, p. 137-176.

MUNAKATA, Kazumi. Educação e modernidade: sob as figuras do relógio e da tipografia. Educar em Revista, Curitiba, n. 18, p. 43-52, 2001.

O DESPERTADOR. Rio de Janeiro, 20 de dezembro de 1840.

PERROT, Michelle. A vida em família. In: HISTÓRIA DA VIDA PRIVADA 4. São Paulo: Companhia das Letras, 2009.

POLLACK, Michael. Memória e identidade social. Estudos Históricos. Rio de Janeiro, v. 5, n. 10, p. 200-212, 1992.

SANTI, Denize Naiara; CASTANHA, André Paulo. O método Lancaster no Brasil: da apologia à crítica. JORNADA DO HISTEDBR, 11. 2013, Cascavel. Anais [...] Cascavel: Unioeste, 2013, p. 1-15. 
SCHUELLER, Alessandra Frota Martinez de. Crianças e escolas na passagem do Império para a República. Revista Brasileira de História. São Paulo, v. 19, n. 37, p. 59-84, 1999.

SOUZA, Gizele de; PERES, Eliane Teresinha. Aspectos teórico-metodológicos da pesquisa sobre cultura material escolar: (im)possibilidades de investigação. In: CASTRO, César Augusto (org.). Cultura material escolar: a escola e seus artefatos. São Luís:

EDUFMA/Café com Lápis, 2011, p. 43-68.

VARELA, Júlia; ALVAREZ-URIA, Fernando. A maquinaria escolar. Teoria e Educação, Porto Alegre, n. 6, p. 68-96, 1992.

VERGER, Jacques. Homens e saber na idade média. Bauru: Edusc, 1999.

VIDAL, Diana Gonçalves. Cultura e práticas escolares: uma reflexão sobre documentos e arquivos escolares. In: SOUZA, Rosa Fátima; VALDEMARIN, Vera Teresa (orgs.). A cultura escolar em debate: questões conceituais, metodológicas e desafios para pesquisa. Campinas: Autores Associados, 2005.

VIDAL, Diana Gonçalves. Escola nova e processo educativo. In: FARIA FILHO et al. (orgs.). 500 anos de educação no Brasil. Belo Horizonte: Autêntica, 2000, p. 497-518.

VIÑAO, Antonio. Historia cultura y historia de la educacion: posibilidades, problemas, cuestiones. Revista Brasileira de Educação. Campinas, p. 64-82, set./dez. 1995.

VIÑAO, Antonio. Las autobiografias, memórias y diários como fuente histórico-educativa: tipologia y usos. Teias, Revista da Faculdade de Educação da UERJ, Rio de Janeiro, v. 1, n. 1, p. 82-97, 2000.

XAVIER, Libânia Nacif. Oscilações do público e do privado na história da educação brasileira. Revista Brasileira de História da Educação, Campinas, n. 5, p. 233-251, jan./jun. 2003. 